\title{
1. Unpacking plain packaging and other standardization requirements in the light of behavioural sciences
}

\section{Alberto Alemanno}

\section{INTRODUCTION}

Plain packaging epitomizes the emergence of a broader, rapidly growing category of regulatory requirements affecting the presentation of products - as diverse as tobacco, alcohol and infant formulas - by standardizing their packaging. While information schemes have existed for a long time, with the aim of overcoming the information asymmetries typical of credence products, the focus of these more recent forms of packagingrelated requirements is now shifting to another policy goal, limiting the consumption of those products that have been identified as unhealthy or at least hazardous due to their constituents and effects. The means used by policymakers to achieve their informational and dissuasive ends include disclosure schemes (for example, labelling), presentation requirements (for example, mandatory warnings and other space appropriation measures) and advertising restrictions (for example, prohibition of use of images, design or brands), whose mutual effect is to standardize the presentation of the final product.

Given the prominent role played by the appearance and certain fancy constituents of the products at issue, as typified by their trade dress, ${ }^{1}$ public authorities seem ready to offset marketing techniques - used since the 1960s - that are increasingly used to market not only tobacco and alcohol but also other less controversial products, such as food and pharmaceuticals. It is in the light of the above that governments around the world are determined to restrict the ability of manufacturers in the

\footnotetext{
1 'Trade dress' refers to the 'look and feel' of a product and can be protected
} in several jurisdictions around the world. 
relevant industries to produce, promote and market their goods as they wish - and to make the products appealing to consumers. ${ }^{2}$

As a result, packaging, and in particular its trade dress, is gradually shaped and physically defined more by the state than by the market. While it progressively appears less of a billboard and more of a leaflet (for example, nutritional labelling and graphic warnings), the progressive standardization of packaging becomes a type of social marketing. ${ }^{3}$

The current efforts at standardizing the package are producing disruptive effects on several legal regimes and, as such, are increasingly contested. ${ }^{4}$ Often referred to by the relevant industries as space appropriation measures, these standardization requirements - ranging from mandatory information schemes to warnings and plain packaging - enter into direct conflict with intellectual property (IP) regimes ${ }^{5}$ in the framework of international trade 6 and investment as well as human rights rules. As such they also give rise to federal disputes at the state and sub-national

2 For an overview of the current state of play when it comes to the implementation of standardized packaging, see note by ASH UK, 16 November 2015 accessed 30 March 2016 at ash.org.uk/files/documents/ASH_960.pdf.

3 Hastings, G, The Marketing Matrix: How the Corporation Gets its Power - And How We Can Reclaim It (Palgrave Macmillan, London 2013).

4 See, among the most recent disputes litigated internationally: Request for Consultations by Ukraine, Australia - Certain Measures Concerning Trademarks and other Plain Packaging Requirements Applicable to Tobacco Products and Packaging, wt/ds434/1, ip/d/30, g/tbt/d/39, g/l/985, 15 March 2012; FTR Holdings SA (Switzerland), Philip Morris Products SA (Switzerland) and Abal Hermanos SA (Uruguay) v Oriental Republic of Uruguay, request for arbitration (ICSID Case no arb/10/7, 19 February 2010, decided in December 2015); Notice of Arbitration, Australia/Hong Kong Agreement for the Promotion and Protection of Investments, Philip Morris Asia Limited, 21 November 2011.

5 Standardization requirements inevitably make difficult the coexistence on the packaging of warnings and other presentation requirements and proprietary elements traditionally protected by IP provisions, whose aim is to distinguish, embellish and/or promote the underlying product.

6 See Request for Consultations (n 4 above). For an analysis of the major legal issues raised by plain packaging and other forms of package standardization, see e.g. Alemanno, A and E Bonadio, 'Do You Mind My Smoking? Plain Packaging of Cigarettes under the TRIPS Agreement' (2011) 10(3) John Marshall Review of Intellectual Property 454; Mitchell, A, 'Australia's Move to the Plain Packaging of Cigarettes and its WTO Compatibility' (2010) 5 Asian Journal of WTO and International Health Law and Policy 405. 
levels, as witnessed by the numerous litigations prompted by the introduction of plain packaging schemes by the $\mathrm{UK}^{7}$ and Eire ${ }^{8}$ within the framework of the European Union (EU) minimum harmonization tobacco packaging presentation requirements. ${ }^{9}$

However, there is more to explore in plain packaging and related standardization requirements than their compatibility with existing legal regimes. ${ }^{10}$ Their introduction also raises a set of second order questions about the legal system, and in particular about the nature of public action. Unlike traditional forms of public intervention aimed at behavioural change, and in particular consumption control, plain packaging and other standardization requirements influence citizens' choices through persuasive, smart and choice-preserving instruments rather than coercion. The approach, which stems from the increasingly ubiquitous findings of behavioural research, ${ }^{11}$ is generally captured under the evocative concept of 'nudge'. ${ }^{12}$ Inspired by 'libertarian paternalism',13 it suggests that the goal of public policies should be to steer citizens towards making positive decisions as individuals and for society while preserving individual choice. As a result, the factual effects of nudge-inspired measures, such as standardization requirements, do not derive from the same

7 On 19 May 2016 the English High Court found the British regulations on standardized packaging proportionate and compliant with intellectual property regimes (British American Tobacco \& others v Department of Health [2016] EWHC 1169 (Admin)). The proceedings were started by several tobacco companies to challenge such legislation. As the decision occurred while this volume was in press, it contains only a few, brief references to the judgment's main findings.

8 Both UK and Irish legislations entered into force on 20 May 2016.

9 Directive 2014/40/EU of the European Parliament and of the Council of 3 April 2014 on the Approximation of the Laws, Regulations and Administrative Provisions of the Member States Concerning the Manufacture, Presentation and Sale of Tobacco and Related Products OJ 2014 (L127/1). See also Case C-547/14, Philip Morris 2015 (Tobacco Products II) nyr; C-358/14, Poland vs Council and European Parliament, nyr; C-477/14, Pillbox 38 nyr (challenging the validity of the 2014 Tobacco Products Directive).

10 For a detailed and insightful analysis of this trend, see Pottage, A, 'No (More) Logo: Plain Packaging and Communicative Agency' (2013) 47 UC Davis Law Review 101-31.

11 Kahneman, D, Thinking, Fast and Slow (Farrar, Straus \& Giroux, New York 2011).

12 Thaler, R H and C R Sunstein, Nudge: Improving Decisions about Health, Wealth and Happiness (Yale University Press, New Haven CT, 2008).

13 Thaler, R H and C R Sunstein, 'Libertarian Paternalism is not an Oxymoron' (2003) 70 University of Chicago Law Review 1159-202. 
coercive force of traditional regulatory intervention, but from their persuasive nature. Their rationale is not to provide meaningful information but to steer people's choices in certain directions regardless of their full informative effect. As a result, the adoption of behaviourally informed public measures raises a panoply of concerns related to their democratic legitimacy, accountability and sustainability over time, which also play a role in the determination of their legality. In particular, an objection commonly raised is that these measures could enter into conflict with the principle of autonomy, that is, the ability to order our lives according to our decisions. By intervening in the human decisionmaking process, behaviourally informed regulation could interfere substantially and be perceived as incompatible with citizens' fundamental rights such as freedom of expression, privacy and self-determination. ${ }^{14}$ Therefore, although behaviourally informed tools appear to be less coercive than conventional regulatory intervention, this does not make less cogent the need to ensure that these tools are subject to appropriate control of public power while regulating citizens' behaviour through persuasive, soft and smart instruments. ${ }^{15}$

This chapter aims at contextualizing the emergence of standardized packaging requirements within the broader phenomenon of behaviourally informed regulation by analysing its promises and pitfalls across the relevant policy areas. The chapter is structured as follows: section 2 addresses the semantic confusion surrounding the controversial notion of 'plain packaging' and strives to offer a more refined terminology of the phenomenon of packaging standardization. Section 3 traces the genesis of plain packaging and the policy diffusion of standardization requirements beyond tobacco. Section 4 identifies the rationales underpinning packaging standardization, while section 5 contextualizes packaging standardization requirements within the broader phenomenon of behaviourally informed intervention. Section 6 discusses the implications stemming from the introduction of nudge-like intervention, such as standardization requirements, to control consumption. Section 7 draws some final conclusions.

14 See e.g. Rebonato, R, Taking Liberties - A Critical Examination of Libertarian Paternalism (Palgrave Macmillan, London 2012).

15 Alemanno, A and A Spina, 'Nudging Legally - On the Checks and Balances of Behavioural Regulation' (2014) 12(2) International Journal of Constitutional Law 429-56. 


\section{THE SEMANTICS OF PLAIN PACKAGING}

As a preliminary remark, it is important to note that packaging standardization is a matter of degree. While mandatory warning (for example, 'Smoking kills you') is a modest form of standardization, plain packaging, rectius full standardized packaging, is an extreme one, as it implies the stripping of eye-catching elements of the brand from the pack. ${ }^{16}$

Obviously, there is a range of other, less intrusive, forms of standardization than the plain packaging scheme that Australia and other countries enacted. Therefore, any attempt at limiting the freedom to design a package through the imposition of some presentation standards, such as a given size, shape, colour and presentation characteristics, automatically translates into a form of pack standardization. As a result of these requirements, the appearance of the products, or at least part of it, may end up being harmonized across a given segment of products. For example, the duty to affix mandatory (graphic and/or pictorial) health warnings, as well as front-of-pack nutritional information on a package, inevitably produces the effect of standardizing the presentation of any given product. This is due to the fact that, as a result of these requirements, the size, colour, font, overall design, and often the positioning of those warnings, are determined by law. As these requirements reduce the ability of manufacturers to design the presentation of their products, all forms of packaging standardization are often referred to, especially by the tobacco industry, as 'space appropriation measures'.

The recently adopted EU Tobacco Products Directive confirms this understanding of the standardization phenomenon. Although it falls short of introducing 'full standardization' (that is, plain packaging), it expressly recognizes that the individual Member States:

'should, under certain conditions, retain the power to impose further requirements in certain respects in order to protect public health. This is the case in relation to the presentation and the packaging, including colours, of tobacco products other than health warnings, for which this Directive provides a first set of basic common rules. Accordingly, Member States could, for example, introduce provisions providing for further standardization of the packaging of tobacco products, provided that those provisions are compatible with the TFEU, with World Trade Organization [WTO] obligations and do not affect the full application of this Directive.' ${ }^{17}$

16 Alemanno, A, 'Out of Sight Out of Mind - Towards a New EU Tobacco Products Directive' (2012) 18(2) Columbia Journal of European Law 197.

17 Recital 53 of the Preamble of the EU Tobacco Products Directive (emphasis added). 
As defined in law by Australia, 'plain packaging', ${ }^{18}$ sometimes also referred to as 'generic' packaging, represents the most extreme form of package standardization since tobacco products are put in drab, purposefully unattractive packaging, devoid of branding (other than name) or promotional information. It can only bear the brand names displayed in a mandated size, font and position. ${ }^{19}$ In Australia, the enacted plain packaging scheme includes some restrictions on size and shape, and the pack must be sold in brown/olive packaging and matt cardboard. There are no special foils, tapes, laminating, or special print effects allowed. Packages are dominated by large and prominent (graphic and textual) health warnings. ${ }^{20}$

\section{THE GENESIS OF PLAIN PACKAGING AND THE DIFFUSION OF STANDARDIZATION REQUIREMENTS BEYOND TOBACCO}

The genesis of plain packaging, rectius full standardized packing, is closely intertwined with the evolution of tobacco control strategies. As is well known, a majority of states have progressively acknowledged the need to regulate tobacco products as a result of the recognition of related adverse public health effects. ${ }^{21}$ As a result, over the years, a significant

18 The Tobacco Plain Packaging Act 2011, which received Royal Assent on 1 December 2011, required all tobacco products sold in Australia to be sold in plain packaging from 1 December 2012. See www.comlaw.gov.au/Details/ C2013C00190 accessed 30 March 2016. The Tobacco Plain Packaging Amendment Regulations 2012, made on 8 March 2012, amended the Tobacco Plain Packaging Regulations 2011 to incorporate additional plain packaging specifications for non-cigarette tobacco products. See www.comlaw.gov.au/Details/ F2013C00801 accessed 30 March 2016.

19 For an overview of the features of generic packaging, see Freeman, B, S Chapman and M Rimmer, 'The Case for the Plain Packaging of Tobacco Products' (2007) 103(4) Addiction 580-90; Alemanno, A and E Bonadio, 'The Case of Plain Packaging for Cigarettes' (2010) European Journal of Risk Regulation 268.

${ }_{20}$ An illustration of how a cigarette pack may look if the draft regulations were introduced is included at Appendix C of the UK Consultation on Standardised Packaging of Tobacco Products: Draft Regulations.

21 WHO, Implementing Smoke-Free Environments, WHO Report on the Global Tobacco Epidemic (WHO, 2009) 8, accessed 30 March 2016 at www.who.int/tobacco/mpower/2009/en. 
range of tobacco control measures has been adopted worldwide. ${ }^{22}$ More recently, these regulatory efforts have been codified within the World Health Organization (WHO) Framework Convention on Tobacco Control (FCTC), the first multilateral health treaty aimed at protecting "present and future generations from the devastating health, social, environmental and economic consequences of tobacco consumption and exposure to tobacco smoke'. ${ }^{23}$ To achieve this goal, the FCTC provides 'a framework for tobacco control measures to be implemented by the Parties at the national, regional and international levels in order to reduce continually and substantially the prevalence of tobacco use and exposure to tobacco smoke'. ${ }^{24}$ Among the regulatory measures that the signatories shall implement, some of them are listed under Article 11 of the FCTC, 'Packaging and labelling of tobacco products' 25 and require the introduction of, inter alia, mandatory warnings occupying a minimum portion of the surface of the pack. The guidelines for implementation of Article 11 recommend the adoption of, inter alia, mandatory plain packaging. ${ }^{26}$

The first record of discussions of generic packaging can be traced back to Canada in 1986, when the Canadian Medical Association (CMA) proposed that cigarettes be sold in the equivalent of plain brown wrappers. ${ }^{27}$ The following year, the CMA called on the federal government to require that 'tobacco products be sold in plain, standard-sized

22 Ibid 64.

23 WHO Framework Convention on Tobacco Control (WHO, 2003) 5, accessed 30 March 2016 at whqlibdoc.who.int/publications/2003/924159 1013.pdf (note that the FCTC became effective on 27 February 2005 and that the treaty, which is now closed for signature, has 174 signatories, including the EU, which makes it the most widely embraced treaty in UN history).

24 Ibid.

25 Ibid 9.

26 WHO, Guidelines for Implementation of Article 11 of the Framework Convention on Tobacco Control, Packaging and Labelling of Tobacco Products (WHO, 17-22 November 2008) para. 46, accessed 30 March 2016 at who.int/ fctc/guidelines/article_11.pdf: (the FCTC Guidelines). Parties should consider adopting measures to restrict or prohibit the use of logos, colours, brand images or promotional information on packaging other than brand names and product names displayed in a standard colour and font style (plain packaging). This may increase the noticeability and effectiveness of health warnings and messages, prevent the package from detracting attention from them, and address industry package design techniques that may suggest that some products are less harmful than others.

27 Cunningham, R, Smoke and Mirrors the Canadian Tobacco War (IDRC Books, Ottawa Ont. 1996) 239. 
packages that state: "This product is injurious to your health". ${ }^{28}$ Some Canadian parliamentarians quickly took up the idea during discussion on the Tobacco Products Control Act in January 1988. ${ }^{29}$ Yet, by that time, only a handful of policymakers or researchers had had an opportunity to evaluate its potential.

Some countries have more recently revived the debate by seriously considering imposing generic packaging on tobacco products. Thus far, Australia, Ireland, ${ }^{30}$ the UK and France ${ }^{31}$ are the only countries to have mandated complete standardized packaging. Indeed, in August 2009, a Bill was proposed to amend both Australia's Trade Practices Act 1974 and Trade Practices (Consumer Product Information Standards) (Tobacco) Regulations 2004 by changing product information standards and removing brands, trademarks and logos from tobacco packaging. ${ }^{32}$ This bill, which was buried by the dissolution of the Australian House of Representatives in September 2010, was reintroduced in the new Parliament $^{33}$ and supported in June 2009 by the publication of the National Preventative Health Taskforce for the Minister for Health and Ageing of a report entitled Australia: The Healthiest Country by 2020, recommending the introduction of various tobacco-related measures, including plain packaging of cigarettes. ${ }^{34}$

28 Physicians for Smoke-Free Canada, The Plot against Plain Packaging (Physicians for Smoke-Free Canada, April 2008), pp. 1-2, accessed 30 March 2016 at smoke-free.ca/pdf_1/plotagainstplainpackaging-apr1'.pdf (outlining the plain packaging time line from June 1986 through 1999 including corresponding debate).

29 Ibid; Cunningham (n 27 above), p. vii.

30 Public Health (Standardised Packaging of Tobacco) Act 2015, accessed 30 March 2016 at oireachtas.ie/documents/bills28/acts/2015/a415-new.pdf.

31 The Standardised Packaging of Tobacco Products Regulations 2015 No 829 was voted on 19 March 2015 and entered into force on 20 May 2016. Accessed 30 March 2016 at www.legislation.gov.uk/uksi/2015/829/contents/ made.

32 Plain Tobacco Packaging (Removing Branding from Cigarette Packs) Bill 2009 (Cth) (Australia) 3-4.

33 Department of the Senate, Canberra, Harry Evans (ed.), Odgers' Australian Senate Practice, 12th edn (CanPrint Communications, Canberra, 2008), pp. 262-64.

34 National Preventative Health Taskforce for the Minister of Health and Ageing, Australia: The Healthiest Country by 2020: National Preventative Health Strategies - The Roadmap for Action (30 June 2009), p. 19, accessed 30 March 2016 at www.preventativehealth.org.au/internet/preventativehealth/ publishing.nsf/Content/nphs-roadmap-toc. 
While by 2016 plain packaging had only been adopted by Australia, ${ }^{35}$ Eire, the UK and France, dozens of countries have enacted mandatory warnings - in line with the FCTC - regarding the presentation of tobacco products. While their size and images differ across those countries, the WHO has successfully promoted minimum standards for the presentation of tobacco products.

As previously anticipated, led by the UK, ${ }^{36}$ Ireland $^{37}$ and France, ${ }^{38}$ several EU Member States, including Belgium, ${ }^{39}$ Sweden and Finland, are currently debating whether or not to introduce plain packaging. It is also under formal consideration in Norway, Hungary, Canada, New Zealand, Singapore, Turkey and South Africa.

Uruguayan legislation prohibits misleading or deceptive tobacco packaging - and thus aims at correctly informing consumers about health consequences. ${ }^{40}$ The declared aim of these measures is to protect people's health. Initially this provision was invoked to outlaw descriptors including 'mild', 'light' and 'ultra-light' (which are typically incorporated in registered trademarks owned by tobacco companies). After Philip Morris began using different brands differentiated by colours and terms referring to such colours instead of the above descriptors (such as 'gold', 'blue', 'silver'), the Uruguayan Ministry of Public Health interpreted the ban on deceptive and misleading packaging so as also to outlaw the use of different colours. Philip Morris challenged this provision under the

35 The Tobacco Plain Packaging Act 2011, which received Royal Assent on 1 December 2011.

36 The Standardised Packaging of Tobacco Products Regulations 2015 No 829 was voted on 19 March 2015 and entered into force on 20 May 2016, accessed 30 March 2016 at www.legislation.gov.uk/uksi/2015/829/contents/ made.

37 Public Health (Standardised Packaging of Tobacco) Act 2015 (n 30 above).

38 See Projet de Loi relatif à la santé, entailing the adoption of plain packaging, accessed 30 March 2016 at www.senat.fr/dossier-legislatif/pj114-406. html. This text was rejected on legal grounds by the French Senate in July 2015.

39 On 19 January 2010, Belgium's Health Minister, in response to a question in the Belgian Parliament, expressed support for plain packaging, including at the EU level. See 19-20 of the following (in French and in Dutch), accessed 30 March 2016 at dekamer.be/doc/CCRA/pdf/53/ac096.pdf. See also the legislative proposal by Catherine Fonck MP (CDH) on standardized packaging, 3 May 2011, available (in French and Dutch) accessed 30 March 2016 at lachambre.be/ FLWB/PDF/53/1424/53K1424001.pdf. The debate is ongoing in front of the Parliamentary Committee on Public Health.

40 Law No 18,256 (2008) (Uruguay) 29 February 2008. 
bilateral investment treaty between Uruguay and Switzerland, ${ }^{41}$ claiming that the way the Uruguayan provision on deceptive and misleading packaging has been interpreted and applied means effectively that just one product from a brand family can be marketed in that country, ${ }^{42}$ with the result that tobacco manufacturers would be unable to fully use their trademark portfolio. ${ }^{43}$ Some commentators have labelled this measure as the 'single presentation requirement', as it bans the presentation of a single brand in multiple forms when those forms may mislead consumers about the risk of smoking. ${ }^{44}$ Philip Morris argues that this measure is arbitrary and not reasonably justified by a public health objective and would thus amount to an unlawful expropriation of (intellectual) property. The dispute is still pending.

Yet packaging standardization requirements are not prerogatives of tobacco products, but extend to several other products, such as alcohol, foods high in fat, salt and sugar (HFSS), pharmaceuticals and infant formulas. Thus, for instance, since 1981, the International Code of Marketing of Breastmilk Substitutes by the World Health Organization prohibits the use of 'any pictures or text which may idealize the use of breast-feeding substitutes' (Article 4.2). ${ }^{45}$

In particular, we are today witnessing some early attempts at implementing standardized requirements on the packaging of alcohol and HFSS food, such as traffic-light systems to convey the nutritional contents. Although in the alcoholic beverages sector neither warning labels nor consumer information measures are very common, ${ }^{46}$ some countries are considering adopting some forms of standardized packaging. Since the notification by Thailand to the WTO Technical Barriers to Trade (TBT) Committee of its proposed combined graphic and pictorial

41 Agreement between the Swiss Confederation and the Oriental Republic of Uruguay Concerning the Reciprocal Promotion and Protection of Investments, signed 7 October 1988, 1976 UNTS 413 (entered into force 7 October 1988).

42 McGrady, B, 'Implications of Ongoing Trade and Investment Disputes Concerning Tobacco: Philip Morris v Uruguay' in Mitchell, A, T Voon and J Liberman (eds), Public Health and Plain Packaging of Cigarettes: Legal Issues (Edward Elgar, Cheltenham UK and Northampton MA 2012) 173 and 178.

43 Ibid.

44 See also WTO, Confronting the Tobacco Epidemic in a New Era of Trade and Investment Liberalization (WTO 2012) 59-60.

45 See on the implementation of the International Code of Marketing of Breastmilk Substitutes in South Africa in Bonadio, this volume, Chapter 2.

46 In the EU, alcohol has been exempted from the obligation to provide allergens and ingredients listing on such products from EU Regulation 1169/ 2011 on the provision of food information to consumers. 
warnings to be affixed to alcohol products, ${ }^{47}$ it appears that imposing labelling requirements on alcoholic beverages may be more controversial than doing so on tobacco products. And Turkey has proposed and recently enacted a similar scheme, ${ }^{48}$ even though it is only textual and not pictorial.

Recent examples also include an EU regulation mandating stricter health warnings on caffeine content in energy drinks. These warnings, either mandated by governments or provided voluntarily by alcohol manufacturers in a number of countries, tend to take the form of reminders about general health risks associated with alcohol consumption, the health risks associated with drinking during pregnancy and the dangers of drinking whilst driving or operating machinery. Labels may also include additional information, such as reference to official drinking guidelines and details of alcohol units or standard drinks. According to the International Center for Alcohol Policies, while there exist today around 20 countries mandating some form of health warning, only Thailand envisages introducing mandatory warnings combining pictorial and textual warnings. The introduction of images seems increasingly crucial because there is evidence suggesting that tobacco companies' efforts to associate themselves with positive images and feelings are effective in mitigating the impact of health warnings. ${ }^{49}$

47 Thailand: Health Warnings for Alcoholic Beverages javascript:link doldoc(G/Tbtn10/THA332.doc,\%20)G/TBT/N/THA/332 and javascript:link doldoc(G/Tbtn10/THA332A1.doc,\%20)Add.1 - concern of US - 11 .

48 As of 11 June 2014, consumers in Turkey are informed about the negative impact that alcohol might have on their health through a set of mandatory warning health messages affixed on alcoholic beverages. Three pictograms inserted on the labels aim to warn these three internationally accepted target groups: minors, drivers and pregnant women. These pictograms should be easily visible and may be affixed anywhere except the bottom of alcoholic beverages. Within this scope, warning messages may be applied on separate stickers, affixed directly on to the packaging. See, WHO http://www.who.int/substance_abuse/ publications/global_alcohol_report/profiles/tur.pdf.

49 See e.g. Lowenstein, G, 'Out of Control: Visceral Influences on Behavior' (1996) 65 Organizational Behavior and Human Decision Processes 272-92; Hanson, J D and D A Kysar, 'Taking Behavioralism Seriously: Some Evidence of Market Manipulation' (1999) 112 Harvard Law Review 1420-569. 
Within the food sector, Chile and Peru proposed the introduction of mandatory 'STOP' warnings on 'high in calories' and 'high salt' food products. ${ }^{50}$

In particular, Chile proposed an amendment to its Food Health Regulation'51 that would place 'skull-and-bones-style' labels on the frontpack of any products considered to be high in sugar, salt, calories and saturated fat. ${ }^{52}$ These warnings would need to be placed in the middle of an octagonal icon (a 'stop' sign) occupying no less than 20 per cent of the main surface of the package, be located in the upper right-hand corner and be at least $4 \mathrm{~cm}^{2}$ in size.

Concerns have been raised that this proposal would create unnecessary obstacles to international trade and, additionally, that it had not been adequately notified to the TBT Committee. In particular, the food industry claims that the warning labels will denigrate various categories of food and drink products, scaring consumers and creating confusion.

Peru adopted similar legislation on 13 May 2013: the Act to Promote Healthy Eating among Children and Adolescents. It aims at adding specific warnings, such as 'high in calories' or 'high salt', on food products. The objective is to inform members of the public of the content of the food they consume in order to encourage individuals to avoid unnecessary, excessive intake which can lead to obesity and related non-communicable diseases. Following their notifications to the TBT Committee, some WTO members emphasized that the Codex had not

50 In the US, California is currently considering a law that would require all sugary beverage products to include a warning label stating 'Drinking beverages with added sugars contributes to obesity, diabetes and tooth decay.'

51 The Draft Amendment to the Sanitary Regulation on Food was presented for an internal public consultation in the beginning of January 2013. In parallel, the authorities of Chile prepared a WTO notification that was circulated to the WTO Members on 16 January 2013 (G/TBT/N/CHL/219). The Draft Amendment and other implementing measures are due to come into force within a year from the adoption of the law. The text of the Draft Amendment is available at www.repositorio.uchile.cl/bitstream/handle/2250/124023/Corvalan-2013-obesityrev.-Ley-chilena-en-Bellagio.pdf?sequence=1, accessed 30 March 2016.

52 The requirement applies to all food products that contain more sodium, total sugars or saturated fat per portion than the thresholds specified in the proposal. For products such as milk, cheese, fish and seafood, rice, pastas and stuffed pastas, meat products, dehydrated soups and broths, margarine and butter, breakfast cereals, confectionery, chocolate, biscuits, snacks and ice-cream, the draft foresees specific, more stringent limits of those nutrients that will trigger the mandatory labelling by means of the STOP sign. The calculation of whether the sign is mandatory for a given product will depend on the size of a portion that needs to be defined in a separate implementing act. 
established thresholds for the nutrients targeted by the Chilean and Peruvian legislation and that these warnings could risk stigmatizing some foods whose moderate consumption formed part of a healthy diet. Moreover, it has been claimed that such warnings would breach the Codex General Guidelines on Claims that prohibits claims on labels which 'could arouse or exploit fear in the consumer'53 as well as the Codex Guidelines on Nutrition Labelling because they would provide a 'simplified categorisation of food products ... which is based on a limited number of nutritional properties'. 54

While the EU has not adopted any schemes for standardizing packaging beyond those enacted in the tobacco sector, the EU Commission has made an attempt at proposing, within the framework of the Consumer Information Regulation, mandatory 'front of pack' nutritional information presented in a 'traffic light' format, in order to facilitate healthier choices 'at a glance', that is without requiring that consumers engage in a thorough reading of the nutrition table on the back of the pack. This format, also termed colour-coded system, uses colours (for example red, amber and green in the traffic light system in the UK; ${ }^{55}$ orange, yellow and green in the Nutri-pass system in France) to indicate whether the nutrient content and sometimes also the energy content of a food product is high, medium or low per $100 \mathrm{~g} / \mathrm{ml}$.

The proposal's objective was to appeal to the average consumer and, by being simple and easy to understand, help that consumer better understand the nutritional information. However, under the pressure of the industry, which perceived this proposal as a threat to its marketing outreach, the EU legislator chose not to support it. Today the Consumer Information Regulation requires mandatory nutrition labelling on the 'back-of-the-pack' but, in addition, provides the possibility of voluntarily indicating nutrition information on the 'front-of-the-pack' in a specified format. ${ }^{56}$

Pharmaceuticals are no exception to the above trend. Indeed, the Australian regulatory agency for medical drugs and devices has recently

53 Codex General Guidelines on Claims (CAC/GL 1-1979).

54 Codex Guidelines on Nutrition Labelling (CAC/GL 2-1985).

55 In the UK, following an agreement struck between the public health ministry and major retailers, food labels should combine traffic-light labels with reference intakes.

56 Article 35 of the Regulation foresees a set of requirements that 'additional forms of expression and interpretation' of nutritional declaration should respect (e.g. based on scientifically valid consumer research, not misleading, facilitating consumer understanding, objective and non-discriminatory, etc.). 
proposed to introduce: (i) a 'medicine information-box' to standardize information formatting; (ii) designated clear spaces on packaging for pharmacists to attach dispensing labels to prescription medicines; (iii) an obligation on pharmaceutical companies to indicate active ingredients on at least three sides of the packaging of medicines with equal prominence to the brand name; (iv) a ban on so-called look-alike and sound-alike medicines such as 'BRAND-headache', 'BRAND-backache' and 'BRAND-joint pain'. ${ }^{57}$

\section{THE RATIONALE OF PLAIN PACKAGING AND OTHER STANDARDIZATION REQUIREMENTS}

Given the prominent role played by the appearance, imagery and general packaging of consumer products (especially of those whose marketing is prohibited or limited), policymakers are increasingly considering the extent to which they should reduce the ability of manufacturers to promote their products as they wish. ${ }^{58}$ In particular, as regulators have become aware of the power of marketing to induce consumer choices, they are reflecting on how they could offset those marketing techniques. In particular, whilst the regulation of product packaging may play an important role in providing important information to consumers, it may also attempt to dissuade consumption. As previously illustrated, this may occur via multiple forms of intervention on the packaging: mandatory consumer information to be affixed to any part of the package; mandatory information in the 'principle field of vision' (also called 'front-ofpack') to appeal to the 'average consumer'; mandatory graphic and/or pictorial warnings; prohibition of the use of brand, design and other

57 The two last measures are discussed by Blum, this volume, Chapter 4.

58 See e.g. World Development Report 2015: Mind, Society, and Behavior (World Bank, 2014); Holland, S, 'Libertarian Paternalist and Public Health Nudges' in Freeman, M et al., Law and Global Health: Current Legal Issues vol. 16 (Oxford University Press, Oxford 2014), p. 331; Marteau, T et al., 'Judging Nudging: Can Nudging Improve Population Health?' (2011) 342 British Medical Journal 263; Glanz, K, B K Rimer and K Viswanath, Health Behaviour and Health Education: Theory, Research and Practice, 4th edn (Jossey-Bass, San Francisco CA 2008); Hastings, G, 'Making Use of Theory' in G Hastings (ed.), Social Marketing: Why Should the Devil Have all the Best Tunes? (Butterworth Heinemann, Oxford 2007), p. 17; Lefebvre, R C, 'Theories and Models in Social Marketing' in Bloom, P N and G T Gundlach (eds), Handbook of Marketing and Society (Sage, Thousand Oaks CA 2000), p. 506. 
decorative elements (plain packaging). What all these measures have in common is to standardize the presentation of the products in the eyes of the final consumer and possibly change his or her consumption patterns.

The rationale underpinning all forms of package standardization is therefore to reduce the attractiveness of the relevant products so as to limit consumption. Thus, in the case of tobacco, the stated objective of standardized packaging is to undermine the allure of smoking, especially for adolescents, in the hope that smoking uptake rates may be reduced. ${ }^{59}$ In particular, this objective is pursued by increasing 'the noticeability and effectiveness of health warnings and messages';60 by preventing 'the package from detracting attention from them';1 and by addressing 'industry package design techniques that may suggest that some products are less harmful than others' and 'attract consumers, promote products and cultivate brand identity' ${ }^{62}$

A similar set of rationales supports current efforts at extending standardization requirements to alcohol and HFSS foods, but with two important distinctions. First, the targeting of the majority of standardization requirements for non-tobacco products is not limited to youngsters, ${ }^{63}$ but extends to a wider segment of the population. Second, besides tobacco, mandatory warnings are not (yet) very common.

Typically, standardization requirements reduce the allure of packaging by, firstly, conveying mandatory negative information about the products available to consumers and, secondly, by reducing the ability of manufacturers to design and present them as they wish. These measures rely on the assumption that, given the proven association between marketing efforts and growing consumption, the introduction of standardized forms of packaging may lower the prevalence of the consumption of the relevant product at either the population or the individual level or both. ${ }^{64}$ As a result of the wide-ranging restrictions imposed on the advertising,

59 McGrady, B, 'TRIPS and Trademarks: The Case of Tobacco' (2004) 3 World Trade Review 53, 57, 66-67.

60 FCTC Guidelines (n 26 above), Article 11.

61 Ibid.

62 Ibid.

63 While in the case of alcohol, it generally extends to drivers and pregnant women, in the case of HFSS food it is addressed to the whole population.

64 See e.g. Kenkel, D and L Chen, 'Consumer Information and Tobacco Use' in Jha, P and F Chaloupka (eds), Tobacco Control in Developing Countries (World Bank and WHO/OUP 2000) 177-214; Ferris Wayne, G and G N Connolly, 'How Cigarette Design can Affect Youth Initiation into Smoking: Camel Cigarettes 1983-93' (2002) 11 Tobacco Control (Supplement 1) i32, i37-38. 
sponsorship and other forms of promotion for tobacco, alcohol, some pharmaceuticals and infant formula products, packaging design has become one of the last remaining opportunities the relevant industries have to promote their products and brands to consumers. ${ }^{65}$ The same cannot be said about HFSS foods, even though several jurisdictions are - in the framework of the WHO Guidelines on Marketing to Children - limiting the possibility for manufacturers to advertise these products to children.

Overall, by reducing the effect of advertising and promotion on packaging, standardization requirements aim to curtail the appeal of given products. In the case of plain packaging, the package eviscerates the entire advertising message and elevates the remaining warnings. It can therefore be characterized as a form of exploitative use of human mental shortcuts by the state, similar to what marketers do when they dress up their products.

\section{UNPACKING STANDARDIZATION REQUIREMENTS IN THE LIGHT OF BEHAVIOURAL SCIENCES}

While it seems undisputed that standardization requirements aim at reducing the attractiveness of the packaging in order to diminish consumption, their nature differs from traditional regulatory interventions targeting behavioural change. The latter typically rely on "command-andcontrol' mechanisms, such as restrictions (for example constraining the use of ingredients allowed) and bans (for example prohibiting consumption), as well as market-based mechanisms, such as adjusting financial incentives (for example raising prices on tobacco and alcoholic products). ${ }^{66}$ Standardization requirements and plain packaging consist, instead, of nudges. A nudge, according to its theorizers, is 'any aspect of the choice architecture that alters people's behaviour in a predictable way without forbidding any options or significantly changing their economic incentives' ${ }^{67}$ However, the exact contours of this innovative approach to

65 See Council Directive 2003/33/, Article 5, 2003 OJ (L 152) 16 on tobacco advertising. See also Alemanno, $\mathrm{A}$ and $\mathrm{E}$ Bonadio, 'Plain Packaging of Cigarettes under EU Law' in Mitchell, A et al. (n 42 above).

66 For an overview of regulatory techniques: Baldwin, R, M Cave and M Lodge, Understanding Regulation: Theory, Strategy, Practice, 2nd edn (Oxford University Press, Oxford 2011); and Hood, C, H Rothstein and R Baldwin, The Government of Risk: Understanding Risk Regulation Regimes (Oxford University Press, Oxford 2001).

${ }_{67}$ Thaler, R H and C R Sunstein (n 12 above), p. 6. 
policymaking are not clear and often differ from the standard definition provided by both academics and public authorities. ${ }^{68}$ Typically, nudges prompt choices without motivating people to consider their options consciously and therefore do not include openly persuasive interventions such as media campaigns and the provision of information. Furthermore, nudges themselves may be provided through regulatory means, as is the case for standardization requirements, and thus are not necessarily an alternative to regulatory tools. By building upon Luc Bovens' proposed taxonomy, a policy instrument qualifies as a nudge when it satisfies the following features:

- its intervention must not restrict choice;

- it must be in the interests of the person being nudged;

- it should involve a change in the architecture or environment of choice;

- it implies the strategic use of some pattern of human irrationality (for example cognitive biases); and

- the action it targets does not stem from a fully autonomous choice (for example lack of full knowledge about the context in which the choice is made). ${ }^{69}$

68 The literature on nudge-type interventions is vast. For a US perspective, see e.g. Vandebergh, M, A Carrico and L Schultz, 'Regulation in the Behavioral Era' (2011) 95 Minnesota Law Review 715. For an EU approach, see Alemanno, A, O Amir, L Bovens, A Burgess, O Lobel, E Salinger and K White, 'Nudging Healthy Lifestyles - Informing Regulatory Governance with Behavioural Research' (2012) 3 European Journal of Risk Regulation 3. For an OECD perspective, 'Consumer Policy Toolkit', see www.oecd.org/sti/consumer/ consumerpolicytoolkit.htm, accessed 30 March 2016. For a contract law perspective, see Bar-Gill, O, Seduction by Contract, Law Economics, and Psychology in Consumer Markets (Oxford University Press, Oxford 2012); for a public health law perspective, Alemanno, A, 'Informing the Non-Communicable Diseases Agenda with Behavioural Insights' in Alemanno, A and A Garde (eds), Regulating Lifestyles - Europe, Alcohol, Tobacco and Unhealthy Diets (Cambridge University Press, Cambridge 2015). For an international law perspective, Broude, T, 'Behavioral International Law' (2013) Hebrew University of Jerusalem International Law Forum Research Paper 12-13, accessed 30 March 2016 at ssrn.com/abstract $=2320375$.

69 Bovens, L, 'The Ethics of Nudge' in Grüne-Yanoff, $\mathrm{T}$ and S Ove Hansson (eds), Preference Change: Approaches from Philosophy, Economics and Psychology (Springer, Berlin and New York 2008). 
If measured against this definition, not only plain packaging but all other standardization requirements seem to qualify as nudges. ${ }^{70}$ This seems to be true in the case of the following:

- graphic warnings (typically portraying dramatic images suggesting a direct link between consumption and death or morbidity);

- front-of-pack information schemes;

- plain packaging (involving the removal of brand, colours and other design features of the product to decrease attractiveness and increase visibility of graphic/textual warnings); and

- prohibition of the use of baby images in the case of infant formulas. ${ }^{71}$

Given the increasing salience of the danger of tobacco smoking, harmful use of alcohol, unhealthy diets or of the superiority of breast-feeding over baby food, none of these policies, not even the health warnings, is going to correct ignorance. Instead, these presentation requirements aim at fighting inertia - by discouraging automatic behaviour - as well as akrasia, namely weakness of will, by breaking social norms.

The non-informational nature of this emerging set of measures is exemplified by the recent decision to remove information regarding tar, nicotine and carbon monoxide yields (commonly referred to as TNCO) from cigarette packs. $^{72}$ By prohibiting the indication of the TNCO information, the idea is to lead smokers towards believing that all

70 For a valuable effort at unpacking the various concepts embedded in the notion of nudging, see Baldwin, R, 'From Regulation to Behaviour Change: Giving Nudge the Third Degree' (2014) 77 Modern Law Review 831.

71 See Articles 4.2 and 9.2 of the International Code of Marketing of Breastmilk Substitutes and Article 10 of Regulation 609/2013 on food intended for infants and young children, food for medical purposes and total diet replacement for weight control OJ L181/35. See also Reg. 7 of R991, published regulations in terms of s. 15(1) of the Foodstuffs, Cosmetics and Disinfectants Act 54 of 1972 in South Africa.

72 Under the original 2003 EU Tobacco Products Directive - which remains in force until 2016 - TNCO labelling should be printed on one side of the cigarette packet in the official language(s) of the Member State where the product is placed on the market so that at least 10 per cent of the corresponding surface is covered. This information is expressly prohibited under the newly adopted EU Tobacco Products Directive. See Directive 2014/40/EU of the European Parliament and of the Council of 3 April 2014 on the approximation of the laws, regulations and administrative provisions of the Member States concerning the manufacture, presentation and sale of tobacco and related products (OJ 2014 L127/1). 
cigarettes are equally dangerous. Because smokers (be they current or future) would no longer find any information about TNCO yields on their packs, they might consider all tobacco products similarly threatening. Yet, interestingly enough, the factor that triggered the idea that 'safer' cigarettes may exist was a reaction to regulatory action aimed at controlling tobacco ingredients by, for instance, establishing maximum levels of TNCO. In particular, the development of low-tar cigarettes has been the tobacco industry's response to increased health concerns. It is no surprise that low-tar cigarettes immediately sparked enduring scientific debates over their supposedly safer use. In particular, by the 1980s the methods commonly used to measure tar and nicotine were found to be limited in accurately reproducing smoking behaviour. ${ }^{73}$ Thus, TNCO information, which is still mandated in Europe and most industrialized countries, is not only incomplete but also positively misleading because it suggests greater safety of low-tar cigarettes. Policymakers around the world have responded with bans on the use of descriptors such as 'light' and 'mild', and in the newly adopted Tobacco Product Directive the EU eliminated the obligation on tobacco manufacturers to display the results of the commonly measured yields from tobacco smoke on products. It is believed that eliminating the existing TNCO quantitative labelling may prevent this information from being misread by consumers who might 'think that lower levels indicate that a product is less risky to their health'. ${ }^{74}$

Moreover, unlike social advertising, packaging standardization requirements are all designed to affect the present choice situation and not future, indeterminate situations. ${ }^{75}$

It is the sum of these features that makes standardization requirements behaviourally informed policy interventions aimed at controlling consumption. We turn now to examine their promises and pitfalls.

73 US Surgeon-General Report, The Health Consequences of Smoking (US Department of Health and Human Services, 1981).

74 European Commission, Public Consultation Document on the Possible Revision of the Tobacco Products Directive (Health and Consumer Protection Directorate-General, 2010) 7.

75 See Bovens (n 69 above). 


\section{THE PROMISES AND PITFALLS OF STANDARDIZATION REQUIREMENTS AS BEHAVIOURAL CHANGE INTERVENTION}

The global appeal of behaviourally informed regulation, which largely explains the rapid diffusion of packaging standardization requirements, is due to several factors. First, the use of behaviourally informed regulatory strategies to control consumption looks like a cheap and smart alternative to traditional expensive regulatory measures, such as taxation, restrictions and prohibitions. ${ }^{76}$ Second, it promises to be choice-preserving, by always enabling the addressee to opt out of the preferred policy option (for example not smoking, not using breastmilk substitutes). ${ }^{77}$ Third, its 'soft' and information-based nature is easy to implement without major changes to the rigid regulatory structure.

But there seems to be a more immediate reason explaining the success of this approach. The rapid proliferation of packaging standardization requirements owes more to the political acceptability of this approach than to its proven empirical effectiveness. As with any other form of mandated disclosure, these presentation requirements carry the potential to address the liberal reservations typically associated with regulatory action vis-à-vis voluntary action. Indeed, unlike paternalists, who ban some things and mandate others, behaviourally informed intervention aims only to skew individual decisions without infringing greatly on freedom of choice. ${ }^{78}$ Plain packaging and other standardization requirements preserve choice. It is indeed undisputable that these requirements, although they typically stigmatize the relevant products, do still allow them on the market.

Yet, while it is argued that this kind of interference is 'lighter' than the bans or other coercive measures linked to traditional techniques of government, it may be difficult to deny that behaviourally informed intervention, such as packaging standardization, would not result in a

\footnotetext{
76 Yeung, K, 'Nudge as a Fudge' (2012) 75 Modern Law Review $122 \mathrm{ff}$.

77 Note that this particular feature of behavioural regulation, by systematically giving rise to 'a pre-commitment to regulatory tools that preserve choice', has been pinpointed as its major weakness by Bubb, R and R Pildes, 'How Behavioral Economics Trims its Sails and Why' (2014) 127 Harvard Law Review 1564-678.

78 'Leader: Soft Paternalism: The State is Looking After You', The Economist (London, 6 April 2006).
} 
restriction on private and natural persons of the capacity to enjoy their freedoms. ${ }^{79}$

\section{The Legitimacy Critique}

Thus, the emergence and diffusion of behaviourally informed regulation raises a fundamental question related to the forms of governmental power. This is because this form of intervention based on public influence and persuasion inherently touches upon the equilibrium of power and liberty in our modern societies. This is by no means to allege that influence and persuasion have not been previously considered to be a form of power, ${ }^{80}$ but rather that a better understanding of the patterns of human decision-making sheds light on precise and concrete mechanisms to modify and control human behaviour.

Moreover, the power to persuade and influence citizens by using behaviourally informed strategies acknowledges the existence of public powers that interfere with citizens' freedoms and the acceptance of this. Making more salient some information (certain nutrients or the superiority of breastmilk over substitute) over other evidence or omitting some or all of that information (as in the case of TNCO) are behaviourally informed choices whose aims justify their means. What counts is what works to attain some (deliberated) legitimate objectives.

However, it appears that, in so doing, behavioural public power is set to interfere with several fundamental rights, such as freedom of expression and, more generally, with the capacity of citizens to enjoy the right to informational self-determination, which is guaranteed by our constitutional traditions.

Ultimately, the legitimacy of nudges depends on citizens' acceptance of the manipulative character of the policy as well as citizens' trust in the 'choice architects', also called 'nudgers'. In other words, the question to be asked is: how comfortable are citizens with having experts and

79 See Alemanno, A and A-L Sibony, Nudge and the Law: A European Perspective (Hart Publishing, Oxford 2015).

80 There is a rather long tradition in state affairs and political science that underlines the concept that influence or reputation is a form of power. $\mathrm{Cf}$. Hobbes, T, Leviathan, JC Gaskin (ed.), Oxford World's Classics (Oxford University Press, Oxford 1996) 58. For a more recent analysis of 'suasion' as a technique of government: Daintith, T, 'Techniques of Government' in Jowell, J and D Oliver (eds), The Changing Constitution (Clarendon Press, Oxford 1994) 209-36. 
bureaucrats designing policy to discourage them from smoking, overeating and using breastmilk substitutes through the strategic use of their cognitive biases?

As previously highlighted, the first answer to this question is that nudges, unlike mandates or bans, retain freedom of choice. By definition, a default rule, such as packaging standardization, enables the addressee to buy and consume that product. Yet, according to some, this is insufficient to legitimize the underlying manipulation of a default change. The classic counterargument is that some kind of nudge is inevitable because default-neutral scenarios do not exist. Thus, contrary to conventional wisdom, default rules, although typically invisible (because people find them so obvious), do not fall from the sky but are the fruit of the deliberate choice of business operators. Therefore, in the public health scenario, the legitimacy of behaviourally informed intervention may be found in the need to offset the negative consequences stemming from the established defaults that do not promote people's interests overall but only the interests of the relevant industries, be they tobacco, breastmilk substitute or others. According to this line of reasoning, if we allow public authorities to make (certain) decisions for us (by merely changing the defaults), we gain not only in personal welfare but also in autonomy. ${ }^{81}$ However, one critical question remains for behaviour change strategies in the area of public health which is: how are targeted population groups involved in the decisions that are taken, as well as in the associated development, implementation, monitoring and evaluation of strategies? This, however, termed the 'publicity principle', should apply to all choice architects, public and private alike. ${ }^{82}$ By the same token, the argument that individuals should take greater responsibility for their health, and adopt healthier behaviours to avoid ill health in later life, appears to be simplistic, if not unrealistic or perceptibly stigmatizing. But there is more.

\section{The Moral Critique}

By aiming at behavioural change through strategic manipulation of cognitive patterns, standardized packaging requirements may not necessarily achieve their objective either through education or through personal will. Two implications stem from this observation. First, there is a

81 See e.g. Conly, S, Against Autonomy - Justifying Coercive Paternalism (Cambridge University Press, Cambridge 2013).

82 Thaler, R H and C R Sunstein (n 12 above) 244. 
risk that the positive effects induced by behaviourally informed intervention would not last. As a result, individuals would be destined to again fall victim to the same behaviours they temporarily abandoned. Thus, while the use of graphic warnings on tobacco products, or even plain packaging, may lead to a decrease in overall consumption, there would be a risk of a 'wear-off' effect, weakening their behavioural effect over time. The other ensuing risk, often formulated as a moral critique, is that behaviourally informed regulations do not build moral character, but rather weaken our capacity for self-control. ${ }^{83}$ People would give up smoking because they were afraid of the appearance of tobacco products or because they no longer see them in plain view, not after having internalized such a decision. In other words, while nudging may produce benefits in the short term, its long-term effect may lead to "infantilization', that is, the decreasing of responsibility in matters regarding one's own welfare.

\section{The Effectiveness Critique}

Apart from this resistance vis-à-vis overall legitimacy of behaviourally informed intervention and its moral acceptability and sustainability over time, the most neglected question - yet probably the most relevant for their legal survival - raised by the introduction of these innovative approaches relates to their effectiveness.

When discussing evidence in the policy process, it is crucial to distinguish between evidence of causes (for example, how reliable, replicable and generalizable are behavioural findings?) and evidence of policy interventions (the potential of behaviourally informed regulations to promote health or reduce harm). Both typologies of evidence are questioned today.

\section{Does the science behind nudging work?}

Critics of the behavioural paradigm argue that both cognitive studies and behavioural economics can show why people might make certain decisions, but they are not robust enough to cover reliable predictions about how people will behave in non-laboratory environments where variable perceptions of meaning exist. ${ }^{84}$ It is indeed undisputable that, by themselves, an understanding of availability heuristics, social influences and

83 Bovens (n 69 above).

84 See also Gigerenzer, G and R Selten, Bounded Rationality (MIT Press, Cambridge MA 2001), p. 10; Selinger, E and K Powys Whyte, 'Competence and Trust in Choice Architecture' (2010) 23 Knowledge, Technology and Policy 
status quo bias, to mention a few, do not always lead to the same conclusions. It may well be that some of these findings may be at work simultaneously in some parts of the population, thus questioning their individual predictive power. As a result, the diverse findings of behavioural research may point in different directions, even within the same subpopulation facing the same problem. In sum, most behavioural insights consist of 'mechanisms rather than law-like generalizations' ${ }^{85}$ For purposes of policy, it would therefore be valuable to have a better understanding of how the major findings of behavioural research apply within heterogeneous groups. Unfortunately, due to methodological and empirical complexity, current research has not been able to address the heterogeneity challenge. 86

\section{Does nudging work?}

Over the years, private economic operators have integrated into their sophisticated consumer and marketing campaigns the idea that environmental and social factors lead to behavioural change. Empirical evidence suggests that ready availability of tobacco, processed foods and alcoholic beverages that are packaged, marketed and engineered to stimulate our automatic, affective system has led us to increase our consumption of those products. ${ }^{87}$ This alone seems to suggest that 'nudging' works. However, this seems to have been proven only when its objective is to worsen people's health. But, what about using the same techniques in order to promote healthier behaviours? To date, few behaviourally informed interventions have been evaluated for their effectiveness in changing behaviour at the population level, and virtually none has been

461-82; Burgess, A, “Nudging” Healthy Lifestyles: The UK Experiments with the Behavioural Alternative to Regulation and the Market' (2012) 3(1) European Journal of Risk and Regulation 3; Powys Whyte, K, E Selinger, A Capan et al., 'Nudge, Nudge or Shove, Shove: The Right Way for Nudges to Increase the Supply of Donated Cadaver Organs' (2012) 12 American Journal of Bioethics 32-9; Selinger, E and K Powys Whyte, 'Is There a Right Way to Nudge? The Practice and Ethics of Choice Architecture' (2011) 5 Sociology Compass 923-35. 85 Sunstein, C R, 'Empirically Informed Regulation' (2011) 78 University of Chicago Law Review 1362.

86 For a reconstruction of this debate, see the introduction by Alemanno, A and A-L Sibony in Nudge and the Law: A European Perspective (Hart Publishing, Oxford 2015).

87 See e.g. Lobstein, T, 'Tackling Childhood Obesity in an Era of Trade Liberalisation' in Hawkes, C, C Blouin, S Henson, N Drager and L Dubé (eds), Trade, Food, Diet and Health: Perspectives and Policy Options (Wiley Blackwell, Oxford 2010). 
evaluated for its ability to achieve sustained change of the kind needed to lead to health gains in the long term. ${ }^{88}$ As previously discussed, the moral critique markedly relies on this state of affairs to question the ability of nudging to attain sustained change over time.

Moreover, it is often contended that it is not only the effectiveness of behaviourally informed regulation that is based on weak, almost anecdotal, evidence, ${ }^{89}$ but also that its real impact may vary across the population, even within the same subgroup, depending on the different cultural and social settings. ${ }^{90}$ To address these and other concerns related to the adequacy of their underlying scientific basis and overall effectiveness, behaviourally informed measures are increasingly tested in a wide variety of behavioural studies. ${ }^{91}$

\section{TOWARDS A NEW PARADIGM IN CONSUMPTION CONTROL POLICIES?}

Packaging is today the most important advertising medium for the tobacco industry because other promotional channels have been shut off. Packaging is becoming equally strategic for other industries, such as that of alcohol, HFSS foods and infant formulas, given the marketing restrictions these sectors increasingly face - hence the efforts undertaken by the health community, followed by public authorities, to hinder those marketing efforts through the introduction of packaging standardization requirements. Although these requirements were originally driven by an

88 Marteau, T, D Ogilvie, M Roland, M Suhrcke and MP Kelly, 'Judging Nudging: Can Nudging Improve Population Health?' (2011) 342 British Medical Journal 263-5.

89 For an early recognition of the lack of both a theoretical and an applied experimental basis for integrating cognitive biases into policymaking, see Eskridge, W and J Ferejohn, 'Structuring Lawmaking to Reduce Cognitive Bias: A Critical View' (2001) 87 Cornell Law Review 616, 647.

90 Sunstein (n 85 above) 1361-2.

91 See the document produced by the UK Government in 2012, Test, Learn, Adapt: Developing Public Policy with Randomised Controlled Trials, accessed 30 March 2016 at www.gov.uk/government/publications/test-learn-adaptdeveloping-public-policy-with-randomised-controlled-trials. 
informational objective, policymakers have progressively realized the inherent limits of mandated disclosure ${ }^{92}$ and have embraced a nudge-type approach.

As a result, what emerges from our analysis of the rapid diffusion of packaging standardization requirements is a new paradigm in consumption control policies. The first generation of measures aimed at behavioural change was based on incentives (such as excise duties) as well as on the provision of detailed information (about product contents and their adverse effects), which assumed that consumers were rational decisionmakers. The individual targeted by those policies was a free, responsible, autonomous subject, capable of making the right choice insofar as he or she received the correct information. With the emergence of a new generation of measures, as epitomized by plain packaging and other standardization requirements, this neoclassical figure of a reasonable decision-maker becomes irrelevant. The idea is to keep consumers away from temptation, by preventing them from being exposed to the appeal of certain products and thus having to make a choice. The choice itself is in no way presented in a balanced, informed way: the act of buying occurs in an entirely new context. Those who want to buy a pack of cigarettes, an item of HFSS food or a breastmilk substitute product find themselves in an entirely new context and, as exemplified by the elimination of TNCO labelling, they tend to receive less information than in the past about the product itself. The focus of the policy intervention is no longer on providing a set of information to enable choice, but on changing the context of choice. As a result, the process through which people get to the desired decision - be it to smoke less or buy less infant formula becomes secondary to the actual optimal choice.

Consumption control policies, as exemplified by packaging standardization requirements, are therefore shifting their focus from mandated disclosure to behaviourally informed intervention. This shift is not entirely surprising today as it belongs to a broader trend. On the one hand, behavioural research has increasingly been questioning the assumption that consumers always react rationally to warnings. ${ }^{93}$ On the other hand, and largely as a result of the very same behavioural sciences, we

92 For an eye-opening critique, see Ben-Shahar, O and C E Schneider, More than You Wanted to Know: The Failure of Mandated Disclosure (Princeton University Press, Princeton 2014).

93 See e.g. Kirby, K N and R Herrnstein, 'Preference Reversals Due to Myopic Discounting of Delayed Reward' (1995) 6 Psychological Science 83-9. 
have been witnessing an emerging scepticism towards mandated disclosure, 'the most common and least successful regulatory technique'. ${ }^{94}$

Despite their promise for changing the social norms, packaging standardization requirements, similar to any other form of behaviourally informed intervention, raise several important concerns, starting from their compatibility with IP regimes. Moreover, they are seldom sufficient to induce change from unhealthy to healthy behaviours for the good of the individual and of society as a whole. While increased awareness, knowledge and a better understanding of changed attitudes are necessary to change behaviour, only a combination of policy instruments, for example, legislation, regulation and even individual financial incentives (positive or negative) and fiscal measures may attain policy objectives. Seen from this perspective, a behaviourally informed approach may complement the emerging regulatory mix of instruments aimed at behavioural change. ${ }^{95}$ There is, however, a risk that a behaviourally informed public action, such as standardization requirements, may fall victim to the so-called 'artificial truncation problem'. ${ }^{96}$ This would occur when the dominant behavioural regulation model, being largely pre-committed to regulatory tools that preserve choice, tends to be blind to more traditional regulatory tools. As a result, public authorities may also refrain from adopting stricter policy interventions when they are needed. The pressure coming from the systematic invocation of IP rights as a shield against the introduction of this new category of measures seems to substantiate such a risk and thus produce what many often define as the 'regulatory chill' effect. In particular, without incorporating behavioural insights into more traditional forms of intervention, it might be difficult to offset the potent effects of unhealthy nudges in existing environments shaped largely by industry. In addition, the current empirical limitations in measuring the effectiveness of behaviourally informed policies in the design of population-wide health interventions seem to represent a major obstacle to their successful implementation.

Although the first evaluation of the experimental application of nudges revealed mixed results, ${ }^{97}$ the implementation of plain packaging in Australia demonstrates promising results. ${ }^{98}$ Both instances illustrate that

\footnotetext{
94 Ben-Shahar and Schneider (n 92 above) 3.

95 For a further illustration of this point, Alemanno (n 68).

96 Bubb and Pildes (n 77 above).

97 Report on Behaviour Change published by the Science and Technology

Select Committee of the UK House of Lords, July 2011.

98 See e.g. Wakefield, M, M Bayly and M Scollo, 'Product Retrieval Time in Small Tobacco Retail Outlets before and after the Australian Plain Packaging
} 
behavioural intervention, which is in its infancy, already offers additional models today. ${ }^{99}$ A similar conclusion was reached by Sir Cyril Chandler in his review of the evidence on standardized packaging. He concluded that:

'... there is enough evidence to say that standardised packaging is very likely to contribute to a modest but important reduction in smoking ... Given the dangers of smoking, the suffering that it causes, the highly addictive nature of nicotine, the fact that most smokers become addicted when they are children or young adults and the overall cost to society, the importance of such a reduction should not be underestimated.'

However, standardization requirements make inherently difficult the coexistence on the packaging of warnings and other presentation requirements and proprietary elements traditionally protected by IP provisions, whose aim is to distinguish, embellish and/or promote the underlying product. While traditional trademark protection used to enable and facilitate consumers' choice, now it must coexist with competing policy objectives, such as to provide guidance about the adverse health effects stemming from (harmful) consumption of the given product. The ensuing challenge is, therefore, how to effectively strike a balance between the economic function conventionally played by trademarks and their emerging social function.

This chapter - when read in conjunction with several of the chapters contained in Part III of this volume - suggests that this emerging category of packaging requirements can, despite their intrusive nature (notably on trademarks), somehow be accommodated within IP regimes.

Policy: Real-World Study' (2013) 23(1) Tobacco Control 70-6; Durkin, S, E Brennan, K Coomber et al., 'Short-Term Changes in Quitting-Related Cognitions and Behaviours after the Implementation of Plain Packaging with Larger Health Warnings: Findings from a National Cohort Study with Australian Adult smokers' (2015) 24 Tobacco Control ii26-ii32; Yong, H-H, R Borland, D Hammond, J F Thrasher, K M Cummings et al., 'Smokers' Reactions to the New Larger Health Warning Labels on Plain Cigarette Packs in Australia: Findings from the ITC Australia Project' (2015) Tobacco Control; Dunlop, S M, T Dobbins, J M Young, D Perez and D C Currow, 'Impact of Australia's Introduction of Tobacco Plain Packs on Adult Smokers' Pack-related Perceptions and Responses: Results from a Continuous Tracking Survey' (2014) 4(12) BMJ Open.

99 Science and Technology Select Committee at the House of Lords, Behaviour Change, 2nd Report of Session 2010-12, 18-19. 